\title{
Parásitos como indicadores cronológicos: ADN antiguo de Nematodirus spathiger (Nematoda: Molineidae) en coprolitos de camélidos de Patagonia argentina
}

\author{
Parasites as chronological indicators: ancient DNA of Nematodirus spathiger \\ (Nematoda: molineidae) in camelid coprolites from Patagonia argentina
}

Romina S. Petrigh ${ }^{1}$, Diego Rindel ${ }^{2}$, Rafael Goñi ${ }^{2} \&$ Martín H. Fugassa $^{3}$

\section{Resumen}

Los coprolitos hallados en los sitios arqueológicos pueden contener restos parasitarios identificables por sus caracteres morfológicos y mediante el análisis de fragmentos de ADN. Este diagnóstico preciso nos permite conocer parte de los ensambles parasitarios de los mamíferos holocénicos. Los coprolitos de camélidos han sido recuperados en diversos sitios de Patagonia. Aquí se informa sobre el análisis de huevos larvados atribuidos a Nematodirus sp. aislados de coprolitos de guanaco del sitio arqueológico Alero Destacamento Guardaparque (ADG) ubicado en la Patagonia Argentina. Los huevos y sus larvas fueron tentativamente asignados por microscopía a Nematodirus spathiger Railliet, 1896 y dicha identidad corroborada mediante el análisis del ADN antiguo (ADNa) de dos aislamientos de huevos larvados. Las secuencias de ADNa obtenidas del fragmento del gen mitocondrial correspondiente a la subunidad I de la enzima citocromo c oxidasa (cox1) mostró un $99 \%$ de identidad con secuencias de N. spathiger. Además, un fragmento del $5.8 \mathrm{~S}$ del ADN ribosomal (ADNr) confirmó estos resultados con un $98 \%$ de identidad. Este parásito no había sido reportado en estudios previos realizados sobre muestras prehispánicas de camélidos, mientras que existen reportes de su presencia en guanacos patagónicos actuales. Nematodirus spathiger es considerado específico de bóvidos y ovinos, lo que sugiere que su ocurrencia en guanacos es resultado de su colonización por enteroparásitos exóticos que llegaron a Patagonia con el ganado europeo. En consecuencia, este hallazgo demuestra su utilidad como indicador temporal para discutir la antigüedad de las capas superiores del sitio arqueológico ADG.

\section{Palabras clave:}

helmintos, sitio arqueológico ADG.

\section{Abstract}

Coprolites from archaeological sites could contain parasitic remains. These remains are identified according to morphological characters and DNA analysis. Accurate diagnosis allows knowing part of the parasitic assemblages of mammals during Holocene. Coprolites of camelids have been recovered in different archaeological sites of Patagonia. In the present work, larvated eggs attribute to Nematodirus sp. isolated from guanaco coprolites were studied to their accurate identification. Coprolites were collected in the archaeological site Alero Destacamento Guardaparque (ADG) located in the Meridional Patagonia. Eggs and their larvae were assigned to Nematodirus spathiger Railliet, 1896 by morphometric analysis under light

1 Laboratorio de Parasitología de Sitios Arqueológicos, Universidad Nacional del Mar del Plata, CONICET.

2 Universidad de Buenos Aires,

Instituto Nacional de Antropología y Pensamiento Latinoamericano, Consejo Nacional de Investigaciones Científicas y Técnicas, Buenos Aires, Argentina.

3 Departamento de Biología,

Universidad Nacional de Mar del Plata. Funes 3350.

Mar del Plata (7600).

$\gg$ mhfugassa@hotmail.com 
microscope. Ancient DNA (aDNA) analysis of two larvated eggs isolates confirmed parasites identity. DNA sequences of mitochondrial fragment of cytochrome c oxidase subunit I ( $\operatorname{cox} 1)$ gene showed a $99 \%$ identity with other $N$. spathiger sequences. Also, sequences of $5.8 \mathrm{~S}$ ribosomal DNA (rDNA) fragment confirmed cox 1 results with an identity of $98 \%$. Previous studies on camelids prehispanic samples not reported $N$. spathiger, but this parasite have been reported in current guanacos in Patagonia. Nematodirus spathiger is considered a specific bovine and sheep parasite suggesting that its occurrence in guanacos is a consequence of host colonization by exotic enteroparasites that arrived in Patagonia with European cattle. Consequently, this finding demonstrates its usefulness as a temporary indicator to discuss the antiquity of the upper layers of the ADG archaeological site.

\section{Key words:}

helminths, ADG archaeological site.

\section{INTRODUCCIÓN}

El examen de coprolitos de camélidos patagónicos ha producido numerosos registros parasitológicos, aunque referidos a unas pocas especies gastrointestinales. Por ejemplo, los 18 niveles estratigráficos del sitio arqueológico Cerro Casa de Piedra 7 (CCP7), ubicado en el Parque Nacional Perito Moreno (provincia de Santa Cruz), resultaron positivos para parásitos, aunque con una baja riqueza de especies. Entre los nematodes hallados, fue recurrente la presencia de huevos atribuidos a un molineido, probablemente Lamanema chavezi Becklund 1963 (Amalfitano et al. 2017). Similares resultados se obtuvieron en el examen de coprolitos de camélidos de un sitio arqueológico lindante, Cerro Casa de Piedra 5 (CCP5) (Taglioretti, 2015) e incluso en el examen de coprolitos de predadores que evidenciaron el consumo de camélidos (Fugassa \& Petrigh, 2017).

En el sitio arqueológico Alero Destacamento Guardaparque (ADG), ubicado próximo a los sitios arqueológicos CCP5 y CCP7 en la Patagonia meridional, se identificaron huevos de L. chavezi en coprolitos de guanaco recuperados de los niveles 3 y 7 (Taglioretti, 2015). Asimismo, en los niveles estratigráficos 3 y 4 se identificaron huevos larvados con buena conservación y que corresponderían a Nematodirus sp., probablemente Nematodirus spathiger debido a las características de las larvas en el tercer estadio de desarrollo (L3) que fueron halladas en los coprolitos (Taglioretti et al. 2017). Nematodirus spathiger es un helminto parásito de ovejas (Soulsby, 1987), su presencia no ha sido reportada en estudios previos realizados sobre muestras prehispánicas de camélidos de Patagonia (Fugassa, 2007; Taglioretti et al. 2015; Amalfitano et al. 2017; entre otros). Asimismo, tampoco se ha reportado $N$. spathiger en muestras arqueológicas de camélidos de otras regiones (Leguía \& Casas, 1999). Sin embargo, N. spathiger fue descrito en poblaciones actuales de guanacos patagónicos (Petrigh \& Fugassa, 2014; Fugassa, 2015). Estos elementos permiten sostener que su presencia en guanacos se debe al proceso de colonización europea y más precisamente, a la introducción y dispersión del ganado ovino en la región. Por lo tanto, resulta ser un indicador cronológico preciso para los coprolitos que contienen huevos o larvas de este nematode.

El objetivo del trabajo consistió en corroborar la identidad específica de este nematode mediante técnicas para el análisis del ADN antiguo, aportando nueva información para la discusión sobre la antigüedad de determinados coprolitos recuperados del sitio arqueológico ADG.

\section{MATERIALES Y MÉTODOS}

Se aislaron huevos compatibles con $N$. spathiger de coprolitos colectados del nivel 4(a) del sitio arqueológico ADG (muestra n574 de la colección del Laboratorio de Parasitología de Sitios Arqueológicos, de la Universidad Nacional de Mar del Plata) y fechado en 890 70 años antes del presente (AP) (766 años calibrados AP, Curva de Calibración para el Hemisferio Sur SHCal13 usando el programa Calib 7.0, Struiver et al. 2014) (Aschero et al. 1992). El sitio arqueológico ADG $\left(47^{\circ} 57^{\prime} \mathrm{S} 72^{\circ} 05^{\prime} \mathrm{O}\right)$ se encuentra dentro del Parque Nacional Perito Moreno en la provincia de Santa Cruz, a $10 \mathrm{~km}$ de la localidad arqueológica Cerro Casa de Piedra (Fig. 1). El sitio ADG es un gran alero (250 m de longitud) situado sobre un cerro de poca altura y orientado hacia el sudeste. Este alero consiste en nueve capas arqueológicas datadas desde la mitad del Holoceno tardío hasta tiempos 


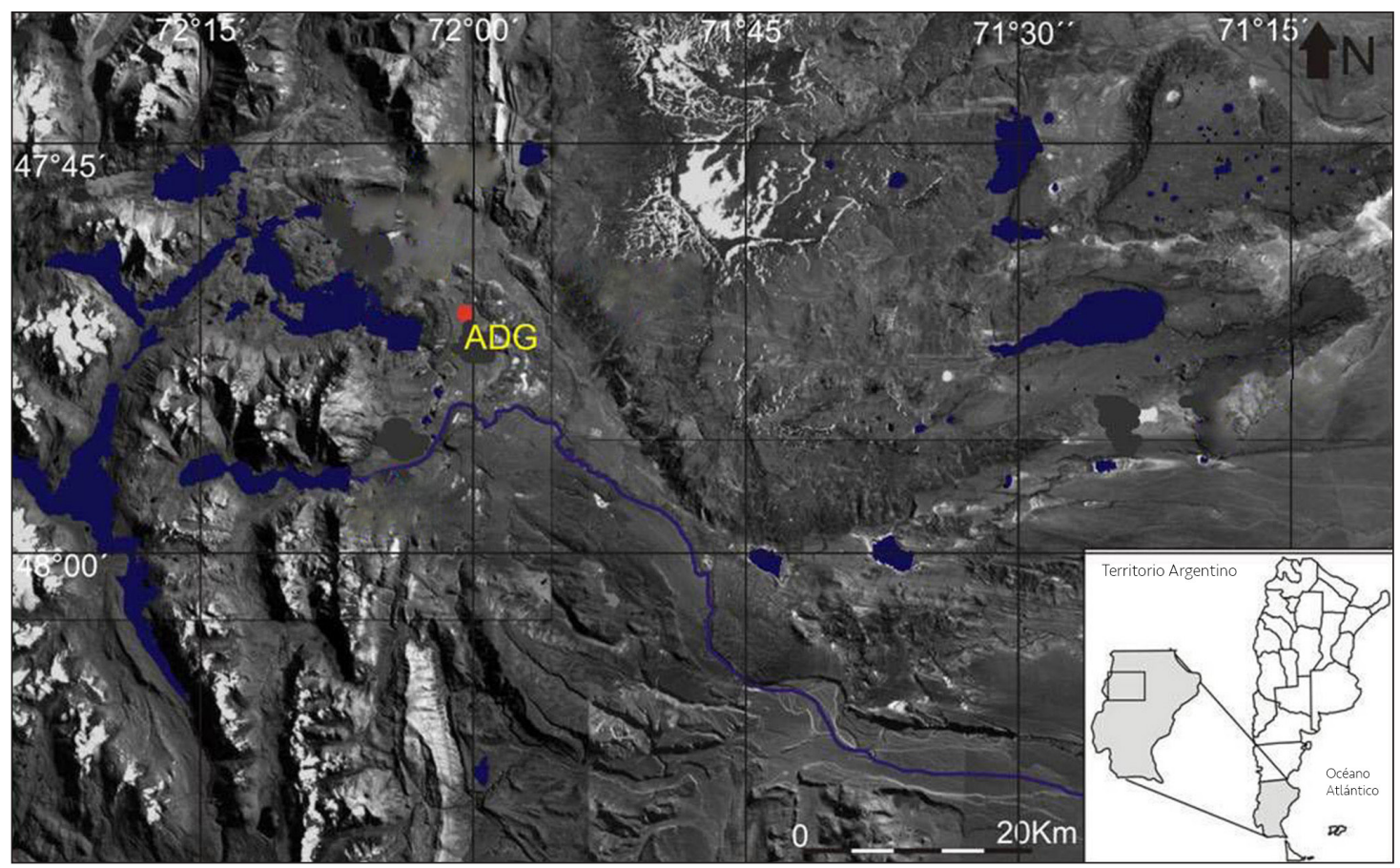

Fig. 1. Ubicación espacial del sitio arqueológico ADG.

históricos. Se reporta la presencia de camélidos en el sitio ADG desde el Holoceno medio -7000 años AP- hasta el período Histórico (ca. 400-100 años AP) (Rindel, 2008). Las capas superiores del sitio (capas 1 y 2) mostraron evidencias de la presencia de ganado europeo (ovino) junto con restos de guanaco (Rindel, 2003).

Los coprolitos fueron asignados a camélidos por su morfología y tamaño (Chame, 2003). Las heces se rehidrataron individualmente en fosfato trisódico acuoso 0,5\% (Callen \& Cameron, 1960) durante 2 días a $4^{\circ} \mathrm{C}$. Posteriormente, se trituraron y tamizaron en una malla con $300 \mu \mathrm{m}$ de apertura. Los huevos hallados fueron aislados manualmente bajo microscopio binocular con un capilar modificado para tal fin (Petrigh \& Fugassa, 2014) y colocados en tubos de $200 \mu \mathrm{l}$ con $5 \mu \mathrm{l}$ de Buffer fosfato salino (PBS) 1x estéril.

\section{RESULTADOS}

Dos huevos larvados (L1 y L2) atribuidos a Nematodirus sp. en base a sus caracteres morfológicos, fueron aislados para corroborar su identificación taxonómica a través de técnicas moleculares. La identificación molecular fue llevada a cabo siguiendo el criterio de autenticidad para determinar secuencias de ADN antiguo (ADNa) (Fulton, 2012). En tal sentido, los reactivos para los análisis de ADNa fueron utilizados exclusivamente para este propósito y, además, cada experimento fue realizado en áreas independientes separadas entre sí (Petrigh \& Fugassa, 2017). El ADNa fue aislado tal como fue descripto en Petrigh y Fugassa (2014). Se utilizó un par de oligonucleótidos específicos: NEM2F (5-GACAGGTTATGTTTATGAT-3) y NEM2R (5-AGGAAAACCATGTAAACCAGC-3) para amplificar con la Reacción en Cadena de la Polimerasa (PCR) un fragmento del gen mitocondrial que codifica para la subunidad I de la proteína citocromo c oxidasa (cox1) de N. spathiger y $N$. oiratianus. Asimismo, un fragmento de la subunidad pequeña $5.8 \mathrm{~S}$ del $\mathrm{ADN}$ ribosomal (ADNr) fue amplificado por PCR utilizando los oligonucleótidos NC13F y NC1R (Chilton et al. 1997). Ambos pares de oligonucleótidos amplifican fragmentos de 100-120 pb, adecuados para amplificar ADNa que frecuentemente se encuentra fragmentado. La PCR se realizó como fue descrita en Petrigh y Fugassa (2017) para ADNa. Se secuenciaron duplicados de cada fragmento específico para cada una de las dos muestras en la Unidad de Genómica del Instituto de 
Biotecnología del CICVyA (INTA Castelar) / Nodo Plataforma de Genómica CATG (Argentina). Los cromatogramas correspondientes a las secuencias fueron analizados mediante el programa BioEdit v7.2.0 (Copyright (c) 1997-2013, Tomm Hall, Ibis Biosciences). Para la identificación de las secuencias de $\mathrm{ADNa}$ se realizaron búsquedas de secuencias homólogas en el banco de secuencias de nucleótidos no redundantes del National Center for Biotechnology Information (NCBI) utilizando el algoritmo BLAST (http://blast.ncbi.nlm.nih. gov/Blast.cgi). El porcentaje de identidad entre dos secuencias (pairwise analysis) fue calculado con el programa LALIGN (Expasy Bioinformatics Research tools).

Se hallaron huevos y larvas atribuibles a Lamanema chavezi (Fig. 2), nematodes específicos de camélidos, lo cual corrobora la asignación de las heces a guanacos mediante su morfología. Asimismo, se observaron y aislaron huevos grandes $(187,5-230[211,397,5 ; n=9] \times 92,5-110[99,17$ $3,75 ; \mathrm{n}=9] \mu \mathrm{m})$, de mayor tamaño al de L. chavezi, elipsoides, de pared lisa, gruesa y traslúcida, siendo compatibles con N. spathiger (Soulsby, 1987). En la mayoría de los casos se halló en el interior de los

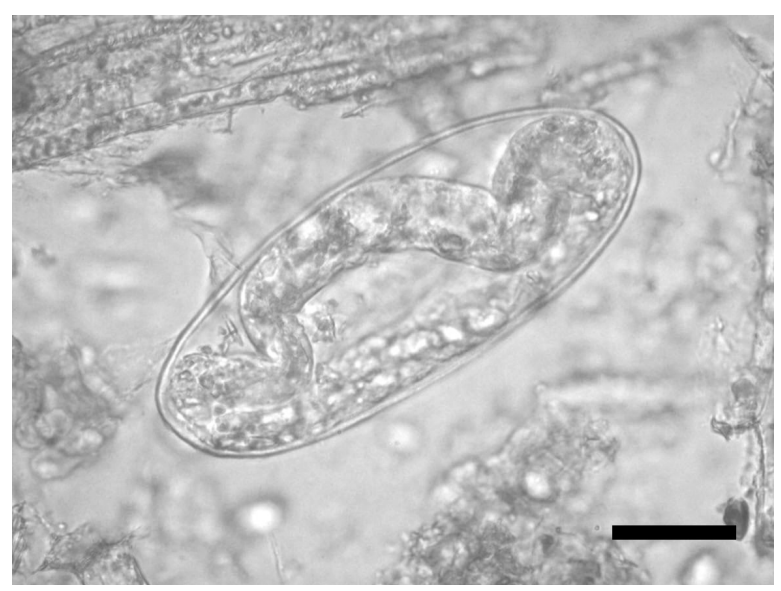

Fig. 2. Huevo compatible con aquellos de Lamanema chavezi de la muestra n574 de ADG. Escala $=40 \mu \mathrm{m}$.

huevos una larva que presentó una vaina caudal larga y en algunos casos pudo observarse la cola bifurcada (Fig. 3) compatible con la de esta especie (Van Wyk \& Mayhew, 2013).

El resultado de la secuenciación de los fragmentos específicos amplificados para los huevos larvados arrojó una secuencia de ADN de 104 pares de bases (pb) del gen mitocondrial cox1. La búsqueda

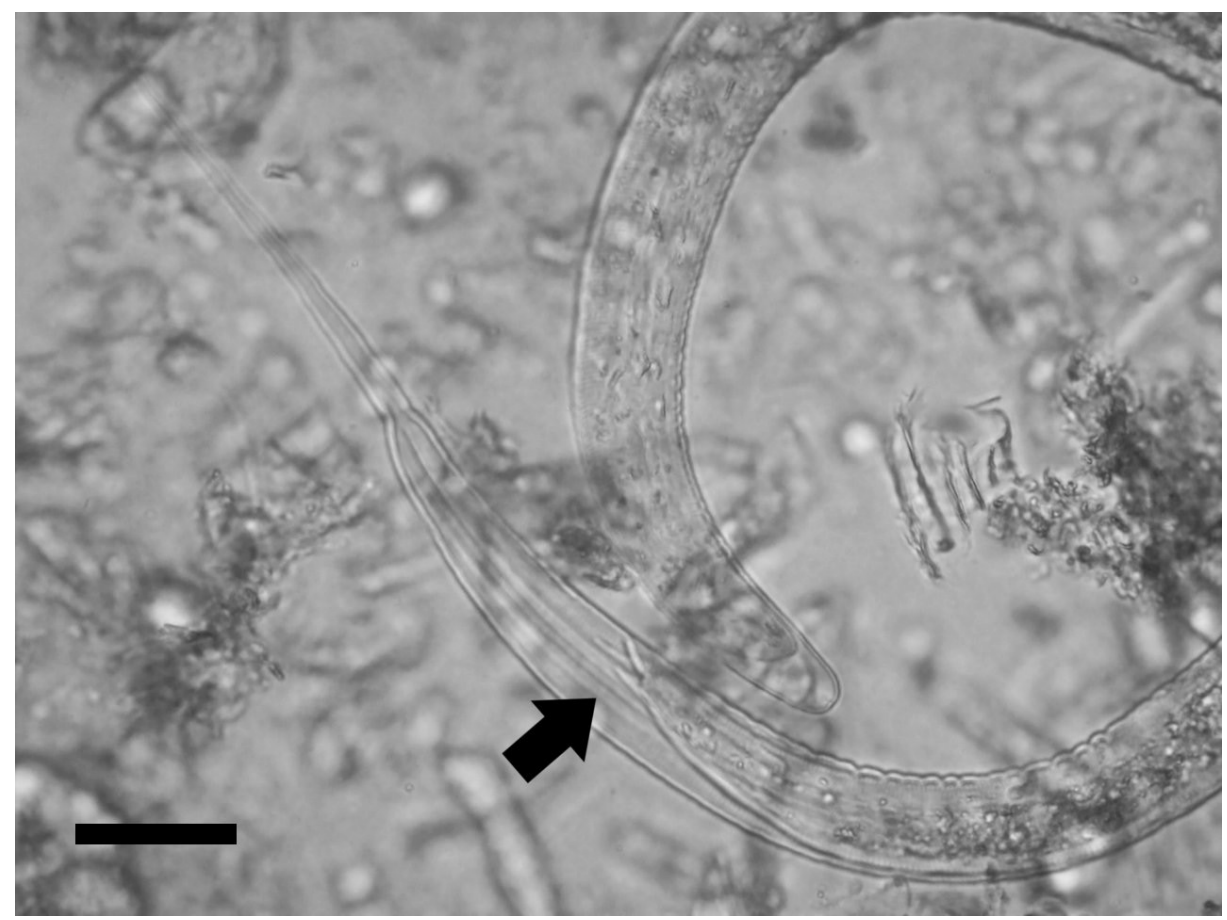

Fig. 3. Detalle de la larva hallada en huevos de Nematodirus spathiger recuperados de coprolitos de la muestra $n^{\circ} 574$ de ADG. Flecha: Detalle de la terminación de la cola bifurcada. Escala $=40 \mu \mathrm{m}$. 
de secuencias homólogas mediante BLAST mostró un $99 \%$ de identidad con secuencias de N. spathiger (Número de acceso del GenBank: KF573749.1) mientras que una identidad del $93 \%$ fue observada con $N$. oiratianus (KF573750.1) otro nematode que parasita pequeños rumiantes (Zhao et al. 2014).

Por otro lado, la secuenciación del fragmento correspondiente al gen 5.8S del ADNr arrojó dos secuencias de 101 pb y 105 pb para cada muestra de $N$. spathiger. La comparación de las dos secuencias con el programa LALIGN mostró un $1 \%$ de diferencias. El análisis de BLAST apoyó los resultados del cox 1 con un $98 \%$ de identidad con N. spathiger.

\section{DISCUSIÓN}

En el presente trabajo se logróla amplificación y secuenciación de ADN mitocondrial y nuclear de parásitos gastrointestinales presentes en coprolitos de camélidos demostrando el buen estado de conservación del ADN en las capas estudiadas del sitio arqueológico ADG. Las secuencias del $\operatorname{cox} 1$ y el 5.8S de N. spathiger del sitio arqueológico ADG fueron publicadas en el GenBank (MG974105; MG974106 and MG974107).

Nematodirus spathiger junto a otras seis especies del género, consideradas específicas de bóvidos u ovinos, fueron halladas en guanacos(Fugassa, 2015), sugiriendo una colonización de enteroparásitos exóticos debido a la invasión del ganado doméstico en Patagonia. Adultos y larvas de N. spathiger fueron hallados en necropsias (Larrieu et al. 1982) y estudios coproparasitológicos de guanacos patagónicos actuales (Moreno et al. 2015). Su presencia en guanacos patagónicos también se corroboró mediante la amplificación de ADN de huevos aislados de heces (Petrigh \& Fugassa, 2014). Entre todos los coprolitos de camélidos examinados de Patagonia, N. spathiger solamente se halló en ADG (en el presente reporte obtenido del nivel 4 y en el estudio de Taglioretti (2015): nivel 3, histórico, muestra $n^{\circ} 532$ ). Debido a la presencia corroborada de $N$. spathiger, puede sostenerse una antigüedad máxima para los coprolitos aquí examinados correspondiente al s. XVIII, durante el ingreso del ganado en la región. La presencia de este parásito también evidencia la complejidad en la formación del registro en este nivel, que tiene fechados de $1510 \pm$
50 (1357 años calibrados AP), $890 \pm 70$ (766 años calibrados AP) y $200 \pm 50$ (175 años calibrados AP) años radiocarbónicos AP (Rindel, 2003; Goñi, 2010). Esto establece una discordancia entre la antigüedad de la capa y los coprolitos presentes en ella. En este trabajo, los parásitos demuestran su utilidad como posibles indicadores temporales y de procesos tafonómicos en coprolitos y sedimentos arqueológicos.

\section{AGRADECIMIENTOS}

Este trabajo fue financiado por: PIP 436, CONICET, PICT 3664, FONCyT, y EXA 777, UNMdP.

\section{LITERATURA CITADA}

Altschul, S. F., Gish, W., Miller, W., Myers, E. W., \& Lipman, D. J. (1990). Basic local alignment search tool. Journal of Molecular Biology, 25, 403-410.

Amalfitano, G., Petrigh, R. S., Loos, J., \& Fugassa, M. H. (2017). Ampliación de los estudios parasitológicos en camélidos del sitio arqueológico Cerro Casa de Piedra 7, Santa Cruz, Argentina. Anales del Instituto de la Patagonia, 45(2), 101-108.

Aschero, C. A., Bellelli, C., \& Goñi, R. A. (1992). Avances en las investigaciones arqueológicas del Parque Nacional Perito Moreno (provincia de Santa Cruz, Patagonia argentina). Cuadernos del Instituto Nacional de Antropología y Pensamiento Latinoamericano, 14, 143-170.

Callen, E. O., \& Cameron, T. W. M. (1960). A prehistoric diet revealed in coprolites. New Scientist, 8(190), 35-40.

Chame, M. (2003). Terrestrial mammal feces: A morphometric summary and description. Memórias do Instituto Oswaldo Cruz, 98, 71-94.

Chilton, N. B., Hoste, H., Hung, G. C., Beveridge, I. \& Gasser, R. B. (1997). The 5.8 S rDNA sequences of 18 species of bursate nematodes (Order Strongylida): Comparison with rhabditid and tylenchid nematodes. International Journal for Parasitology, 27(1), 119-124.

Fugassa, M. H. (2007). Camélidos, parásitos y ocupaciones humanas: Registros 
paleoparasitológicos en Cerro Casa de Piedra 7 (Parque Nacional Perito Moreno, Santa Cruz, Argentina). Intersecciones en Antropología, 8, 265-269.

Fugassa, M. H. (2015). Checklist of helminths found in Patagonian wild mammals. Zootaxa, 4012(2), 271-328.

Fugassa, M. H., \& Petrigh, R. S. (2017). Apex predators, rockshelters, and zoonoses in the Patagonian Holocene. The Journal of Parasitology, 103(6), 791-794.

Fulton, T. L. (2012). Setting up an ancient DNA laboratory. En B. Shapiro, M. Hofreiter (Eds.), Ancient DNA, Methods and Protocols (pp. 1-11). Nueva York: SpringerHumana Press.

Goñi, R. A. (2010). Cambio climático y poblamiento humano durante el Holoceno tardio en Patagonia meridional. Una perspectiva arqueológica. Tesis de doctorado. Buenos Aires, Argentina: Facultad de Filosofía y Letras, Universidad de Buenos Aires.

Larrieu, E., Bigatti, R., Lukovich, R., Eddi, C. S., Bonazzi, E. F., Gómez, E.,... \& Oporto, N. R. (1982). Contribución al estudio del parasitismo gastrointestinal en guanacos [Lama guanicoe] y llamas [Lama glama]. Gaceta Veterinaria, 44(374).

Leguía, G., \& Casas, E. (1999). Enfermedades parasitarias y atlas parasitológico de camélidos sudamericanos. [Parasitic diseases and parasitological atlas of South American camelids]. Knowledge of the South American camelids]. FAO Regional Office for Latin America and the Caribbean, 387-412.

Moreno, P. G., Schroeder, N. M., Taraborelli, P., Gregorio, P., Carmanchahi, P. D., \& Beldomenico, P. M. (2015). La comunidad de parásitos gastrointestinales de guanacos silvestres (Lama guanicoe) de la reserva provincial La Payunia, Mendoza, Argentina. Mastozoología neotropical, 22(1), 63-71.

Petrigh, R. S., \& Fugassa, M. H. (2014). Molecular identification of Nematodirus spathiger (Nematoda: Molineidae) in Lama guanicoe from Patagonia, Argentina. Helminthologia, 51(2), 79-82.

Petrigh, R. S., \& Fugassa, M. H. (2017). Improved coprolite identification in Patagonian archaeological contexts. Quaternary International, 438, 90-93.

Rindel, D. D (2003). Patrones de procesamiento faunístico durante el Holoceno medio $y$ tardio en el sitio Alero Destacamento Guardaparque (Parque Nacional Perito Moreno, provincia de Santa Cruz, Argentina). Tesis de licenciatura. Buenos Aires, Argentina: Facultad de Filosofía y Letras, Universidad de Buenos Aires.

Rindel, D. D. (2008). Arqueología de Momentos Tardios en el Noroeste de la Provincia de Santa Cruz (Argentina): Una Perspectiva Faunística. Tesis de doctorado. Buenos Aires, Argentina: Facultad de Filosofía y Letras, Universidad de Buenos Aires.

Soulsby,E. J. (1987). Parasitología yenfermedades parasitarias (pp. 40-44). México, D. F: Nueva Editorial Interamericana.

Stuiver, M., Reimer, P. J., \& Reimer, R. W. (2014). Calib Radiocarbon calibration 7.0. World Wide Web: http://calib.qub.ac.uk/calib/. Accessed 1 April 2019

Taglioretti, V. (2015). Estudios paleoparasitológicos en coprolitos de camélidos sudamericanos. Tesis de doctorado. Mar del Plata, Buenos Aires, Argentina: Departamento de Biología, Facultad de Ciencias Exactas y Naturales, Universidad Nacional de Mar del Plata.

Taglioretti, V., Fugassa, M. H., \& Sardella, N. H. (2015). Parasitic diversity found in coprolites of camelids during the Holocene. Parasitology research, 114(7), 2459-2464.

Taglioretti, V., Fugassa, M. H., Rindel, D., \& Sardella, N. H. (2017). New parasitological findings for pre-Hispanic camelids. Parasitology, 144(13), 1763-1768.

VanWyk, J.A., \& Mayhew, E. (2013). Morphological identification of parasitic nematode infective larvae of small ruminants and cattle: A practical lab guide. Onderstepoort Journal of Veterinary Research, 80(1), a539, DOI: https://doi.org/10.4102/ojvr.v80i1.539

Zhao, G. H., Jia, Y. Q., Cheng, W. Y., Zhao, W., Bian, Q. Q., \& Liu, G. H. (2014). Characterization of the complete mitochondrial genomes of Nematodirus oiratianus and Nematodirus spathiger of small ruminants. Parasites \& vectors, 7(1), 319. 